\title{
The Levels of Vocational Identity
}

\author{
Zahraa Mahmood Alkhateeb, Prof. Dr. Mohammed Kazem Aljizani \\ College of Basic Education - Al-Mustansiriya University
}

DOI: $10.37648 /$ ijrssh.v10i04.046

Received:10 ${ }^{\text {th }}$ August, 2020; Accepted:18 ${ }^{\text {th }}$ September, 2020; Published: 26th December, 2020

\begin{abstract}
The current research aims to identify the Levels of Vocational Identity for educational counselors, as the research consisted of (400) guides and guides. The researcher built a The Levels of Vocational Identity scale based on Holland theory ) The researcher used the statistical methods: T-test for one sample ( $T$ _test), T-test for two independent samples, Pearson correlation coefficient, and the current research results showed that educational counselors have a high professional identity and in favor of the social level, and in the light of the findings of the researcher presented a number of recommendations and suggestions.
\end{abstract}

\section{CHAPTER 1 : THE STUDY PROBLEM}

Perhaps the issue of identity at work is among the most complex issues as it is the outcome of relationships and interaction with management and colleagues, as it defines the professional group to which he belongs, allowing the individual to determine his position within the organizational system. The individual's failure to possess a professional identity leads to laziness at work and the individual's lack of awareness of his duties. And what is required of him, each individual presents himself based on the profession he practices. (Muhammad, 2014: 1)

Holland has indicated that there is a fit between the environment in which the individual lives and his profession, and often the individual's knowledge of himself and the environment is acquired subconsciously. And that the individual's choice of his profession is the result of a group of forces, which includes a hierarchy of his choice. Holland also spoke about the necessity of a harmony of the individual's capabilities with the requirements of the environment, and this matter depends on the personality and the environment being of the same type and why each individual has a lifestyle that is determined based on his values, inclinations and preparations And his personality traits, intelligence, and his concept of himself, as this method helps a person direct him to varying degrees towards different professional environments. (Al-Shurafa, 2011: 42)

Holland (1980) also believes that identity refers to the clarity and stability of the individual's current and future goals and stability in the professional environment, and that institutions define their identity with the tasks and goals of the profession and the worker who performs them (Abu Attia, 2015: 44)

research importance :

The identification of a professional identity is one of the important factors on which the success or failure of the individual in the professional field depends, as the professional identity prepares the individual to realize the practical tasks and professional belonging and to reinforce the values contained in the identity. (Davey) points out that professional identity is formed in multiple contexts that bring personal, social, cultural, political and historical power to influence this formation. Many researchers say that the professional identity does not come ready-made, but rather is constantly being formed in temporary situations (Webb, 2017: 20). The results of Hussein's study (2017) also showed the clarity of the meaning of the professional identity of the teacher among the study sample without knowing the concept and that they have high levels of professional identity (Hussain, 2017: 84). The results also indicated for the Mishri study (2018). It is governed by his professional identity $\operatorname{rank}($ Meshri, 
2018: 79) Al-Khatib, 2005, notes that the development of identity coincides with the cognitive and social maturity of the individual (Al-Zubaidi and Al-Kahali, 2014: 32)

Through the foregoing, the importance of the current research lies in its attempt to fill the gap in studies related to levels of professional identity, as this research derives its importance from the following theoretical and applied considerations:

First / The theoretical importance is represented by the following:

1-The importance of the concept of professional identity,It is important for the individual to have a career orientation, knowledge and awareness of all its details

2-Highlight on a relatively recent topic and try to get acquainted with all the information related to it (Concept, dimensions, theories).

Second / Application importance is represented by the following: -

Preparing and building a scale (professional identity) for educational counselors.

The applied importance of the current research is determined in finding the relationship between levels of professional identity and what it can reach in terms of results and conclusions related to this variable.

\section{Objectives of Research:}

1-Building a measure of Levels of professional identity for educational counselors.

Levels of professional identity for educational counselors. Search Limits:

The objective limit: The current research is limited to dealing with the concept of levels of professional identity. 2. Spatial limit: The current research is determined by the education directorates of the Baghdad governorate (Rusafa 1, 2, 3, and Al-Karkh 1, 2 and 3).

3. Time limit: The current research will be conducted during the 2019-2020 academic year.

4. The human limit: counselors and educational guides.

Definition of Concepts

First: The Levels of Vocational Identity

The Charter 2010

The ability of the individual to determine his career path, based on his knowledge of himself, i.e. his knowledge of his capabilities and professional potential and his knowledge of the requirements of the world of work (Meshri, 2018: 86).

Brown \& lent2015
How clear the image an individual has about their current career plans, goals, tendencies, talents and abilities (2015, Brown, \& lent).

Rachel Bird 2015

A reflexive and continuous process of construction, dismantling, and reconstruction, and thus it is a dynamic process that develops with the development of societies and influences the individual's understanding of his role and functional identity (Baird, 2018: 465).

Theoretical definition: The researcher adopted a definition (Brown \& Lent, 2015), a theoretical definition, as it is the closest to the current research.

Procedural definition

It is the total score that the respondent obtains by answering the professional identity scale used in the current research.

Secondly : Educational Counselor

The Ministry of Education's definition of an educational guide (1988):

$\mathrm{He}$ is one of the faculty members qualified to study students 'educational, health, social and behavioral problems through all the information related to these problems, whether this information is related to the student or the environment surrounding him. To choose the appropriate solution that he accepts for himself (Ministry of Education, 1988: 10)

\section{THE SECOND CHAPTER:}

\section{THE THEORETICAL FRAMEWORK AND PREVIOUS STUDIES}

The individual's sense of belonging to an institution characterized by a special identity and a special cultural model is considered a psychological and social factor in motivating him and facilitating the process of direct communication and integration into cooperative work for a common goal which is the development of the institution and thus the development of its members (Amina, 2012: 94) Identity and Haniyeh is a dimension of social identity, but it is effective at the appropriate time, because the reactions of this person in the social areas in which he is present and active within them, and they are considered from the point of contact, 2019: 858). The professional identity is a dimension of the dimensions of the person's psychological and social identity, but at the same time it is specific to the patterns of this person's interactions in the social fields in which he is present and 
is active within them., 2019: 858). Holland has expressed the professional identity by the extent of clarity of the image that the individual possesses about his current career plans, goals, tendencies, talents, and abilities, or, more simply, where the individual falls into professional awareness (Al-Masoud and Watanous, 2015: 87).

\section{Dimensions of professional identity}

Wenger defined it in 1998 as follows:

1_ Identity as a negotiated experiences

2- Identity as membership in society

3- Identity as a path to learning

Identity as a relationship between multiple memberships (Al-Khouli, 2018: 473).

The idea of professional identity is considered an attempt by Hollande to refine his theory, as it establishes the clarity of the image that the individual possesses about his current career plans, goals, tendencies, talents and abilities, or, more simply, where the individual falls into the professional awareness. Holland has proposed six occupational environments corresponding to six personality styles, the first called the occupational environments and the second the hierarchical development of personality traits, and this hierarchical development represents the individual's adaptation to the six occupational environments. The six occupational environments have been given the same names of personal styles (Abdulaziz and Atwi, 2004: 154_155). Holland assumes that people can be classified on the basis of how similar their personal traits are into several types, and the environments in which they live can be classified into several types on the basis of the similarity of these environments to each other (Al-Hadi and Al-Ez, 2014: 62). Holland's theory is also called (RIASEC theory) and is an acronym for the six types of personalities and environments known in Holland's model (Jungers, 2013: 292).

\section{These patterns, levels, and environments are:}

1- Realistic environment: Individuals in this environment tend towards activities that require coordination, strength and physical skill. They prefer action and action over thinking, and they are characterized by being practical in dealing with life's problems.

2- $\quad$ The mental environment: they prefer to think about solutions to problems rather than act upon them, and they tend to organize and understand more than authority. They are interested in searching for the causes of things and their relationships.

3- The social environment: It is represented by the owners of the social orientation, and the people within this environment are characterized that they possess verbal skills and skills related to social relations to achieve their professional goals. (Al-Azza and Abdel-Hadi, 2012: 63_64).

4- $\quad$ Traditional environment: Individuals in such an environment are common to engage in activities that require order and accuracy in processing information that are beneficial to them, as individuals see themselves as committed, regular and competent in office activities.

5- $\quad$ The adventurous environment: the adventurous people work in it and this environment values power, status and responsibility and encourages individuals to see the world with relative simplicity.

6- The artistic environment: This gives value to free, ambiguous and irregular activities. It also encourages individuals to see themselves as creative, noncommittal and possessing artistic capabilities of a distinctive kind.

\section{Previous studies:}

1-Al-Zubaidi and Al-Kahali 2014

(Differences between gender and grade and anxiety in cases of professional identity among ninth and tenth grades students in the Sultanate of Oman)

This study aimed at identifying the professional identity of students of the ninth and tenth grades in public education schools in the Sultanate of Oman, as well as identifying the differences in professional identity according to the gender variable, the grade variable and the anxiety variable. A professional identity scale consisting of 20 items was prepared, and the study sample consisted of 255 male and female students, of whom 143 were from the ninth grade and 112 from the tenth grade. 
The results concluded that the ranking of the professional identity of the ninth and tenth grade students is as follows(Restricted Identity, Ambiguous Identity, Deferred Identity and Collected Identity)and There were statistically significant differences in the restricted and ambiguous identity attributed to the gender variable in favor of females and indicated the presence of statistically significant differences in the collected, deferred and restricted identity in favor of tenth grade students and the absence of statistically significant differences for the anxiety variable (Al-Zubaidi and Al-Kahali, 2014: 31).

\section{2-Hussein Study 2017}

(Survey of occupational identity levels of primary school mathematics teachers)

The aim of the research was to investigate the levels of the professional identity of the teacher among mathematics teachers at the elementary level. The research was conducted on a sample of 129 teachers, electronically distributed to them a scale to determine the level of professional identity, and 20 of them conducted an individual personal interview to determine the mathematics teachers 'perceptions of the professional identity of the teacher, The results indicated the clarity of the meaning of the professional identity in the study sample without their knowledge of the concept, that their levels of professional identity are high, and that there is no difference between the levels of professional identity in the research sample due to the type or years of experience or the number of professional development programs obtained (Hussein, 2017: 84)

\section{3-The 2018 Meshry study}

(The teacher's professional identity and its relationship to commitment to professional ethics)

The aim of the research is to reveal the relationship between the formation of the professional identity of the teacher and his commitment to the ethics of the teaching profession, according to a psychological perspective in the framework of Eric Erikson's work on the identity crisis and what James Marsha presented on the concept of commitment to roles, values and professional principles and to discuss them in light of the reality of the teaching profession in the Arab world in general. To submit proposals to shape the personality of the teacher before and after joining the teaching profession.

\section{CHAPTER III : METHOD OF THE RESEARCH}

The researcher followed the descriptive approach that depends on the study of reality or phenomenon as it exists in reality, and is concerned with describing it accurately (Mcmillan \& Schumacher, 2001: p: 29).

Population of the Research

The current research community consisted of educational counselors and of both genders present in elementary, intermediate, preparatory, and secondary schools affiliated to the General Directorates of Education in Baghdad Governorate (Rusafa I, Rusafa II, Rusafa III, Karkh I, Karkh II and Karkh III) morning study for the academic year (2019-2020), totaling (1840) male and female guides, distributed by gender, with (629) male and female mentors (1211) male and female mentors, Table (1) illustrates this.

Table (1)

The research community is distributed according to the General Directorates of Education and gender

\begin{tabular}{|l|l|l|l|l|}
\hline \multirow{2}{*}{ Numbering } & \multicolumn{2}{|l|}{$\begin{array}{l}\text { General Directorate of } \\
\text { Education, gender } \\
\text { Governorate }\end{array}$} & & \multicolumn{2}{|l}{ Total } \\
\cline { 3 - 5 } & & Males & Females & \\
\hline 1 & & & & \\
\hline 2 & Al-Rusafa 1 & 96 & 255 & 351 \\
\hline 3 & Al-Rusafa 2 & 108 & 222 & 330 \\
\hline
\end{tabular}




\begin{tabular}{|l|l|l|l|l|}
\hline 4 & Al-Karkh 1 & 91 & 188 & 279 \\
\hline 5 & Al-Karkh 2 & 91 & 244 & 335 \\
\hline 6 & Al-Karkh 3 & 150 & 201 & 351 \\
\hline Total & 629 & 1211 & 1840 \\
\hline
\end{tabular}

\section{Sample of the Research}

It is a partial group of the research community and represents the best representative of the community elements, so that the results of that sample can be generalized to the entire community and make inferences about community features (Abbas and others, 2016: 218). The research samples will be presented as follows: -

\section{1-Sample Statistical Analysis}

Table (2)

Distribution of research sample individuals (statistical analysis) according to the name of the directorate and gender.

\begin{tabular}{|l|l|l|l|l|}
\hline \multirow{2}{*}{ Numbering } & $\begin{array}{l}\text { General Directorate of } \\
\text { Education, } \\
\text { Governorate }\end{array}$ & & \multirow{2}{*}{ gender } \\
& & \multicolumn{2}{|l|}{ Total } \\
\cline { 3 - 5 } & & Males & Females & \\
\hline 1 & & & & \\
\hline 2 & Al-Rusafa 1 & 41 & 61 & 102 \\
\hline 3 & Al-Rusafa 2 & 48 & 56 & 104 \\
\hline 4 & Al-Rusafa 3 & 27 & 30 & 57 \\
\hline 5 & Al-Karkh 1 & 15 & 19 & 34 \\
\hline 6 & Al-Karkh 2 & 26 & 12 & 38 \\
\hline Total & Al-Karkh 3 & 43 & 22 & 65 \\
\hline
\end{tabular}

\section{2-Application sample}

Table (3)

Distribution of the application sample personnel according to the directorate name and gender

\begin{tabular}{|l|l|l|l|l|}
\hline \multirow{2}{*}{ Numbering } & $\begin{array}{l}\text { General Directorate of } \\
\text { Education, } \\
\text { Governorate }\end{array}$ & gender & \multirow{2}{*}{ Total } \\
\cline { 3 - 5 } & & Maghdad & \multicolumn{2}{|l|}{} \\
\cline { 3 - 5 } & & & & \\
\hline 1 & Al-Rusafa 1 & 20 & 30 & 50 \\
\hline 3 & Al-Rusafa 2 & 24 & 28 & 52 \\
\hline
\end{tabular}




\begin{tabular}{|l|l|l|l|l|}
\hline 4 & Al-Karkh 1 & 8 & 10 & 18 \\
\hline 5 & Al-Karkh 2 & 13 & 6 & 19 \\
\hline 6 & Al-Karkh 3 & 21 & 11 & 32 \\
\hline Total & 100 & 100 & 200 \\
\hline
\end{tabular}

\section{Tools Of The Research}

To achieve the objectives of the current research, it required preparing a scale for professional identity levels, and the researcher prepared a scale for professional identity levels as follows:

The researcher relied on Hollande's definition of a professional identity according to his theory that it is (the clarity of the image that the individual has about his current career plans, his goals, his inclinations, talents and abilities) or, more simply, where the individual falls into the professional awareness through which the individual can be assessed whether he possesses a vision Clear his career goals and the tasks needed to make the perception clear.

\section{Determine the areas of scale}

1- Realistic environment: it is an environment that depends on physical sensory activities and requires mechanical skills, persistence and physical movement.

2- The artistic environment: it is the environment that requires the creative use of artistic guides, such as the use of knowledge, intuition, emotion, reliance on subjective and personal criteria in judging information.

3- The social environment: It is the environment that requires the ability to change human behavior, the desire for attention, a sense of responsibility, teamwork, and positive communication with students and their parents.

4- The traditional environment: It is the environment that requires regular, routine and concrete dealing with verbal information by following clear procedures.

5- Mental environment: It is the environment that requires the use of abstract and creative mental abilities instead of personal perceptions

6- Adventurous environment: It is the environment that requires verbal skills to direct or persuade others, a tendency to adventure, and work that requires directing or planning or controlling activities performed by others (Abdel-Aziz and Ataiwi, 2004)

7 -

\section{Drafting the scale paragraphs}

The professional identity scale was built by referring to previous studies. (50) paragraphs were formulated as they were divided into the six domains by (8) items for the real environment field, (8) items for the technical environment field, and for the social environment field (9) paragraphs, and (7) ) Paragraphs in the field of traditional environment and (10) paragraphs in the field of mental environment and (8) paragraphs in the field of adventure environment

\section{Instructions for the two scales}

The scale instructions are considered the guide that guides the respondent, so it was taken into account in preparing the scale instructions that they be clear, simple and understandable, and a sign $(\checkmark)$ is placed under the choice that applies to the respondent, and the researcher confirmed the confidentiality of the answer, and not asking the respondent to mention the name and use the answer for the purposes of scientific research Just.

Statistical analysis of the scale paragraphs

1_ Distinguish paragraphs

For the purpose of extracting the discriminatory power of the paragraphs, the (50) paragraphs of the scale were applied to a randomly selected sample from the research community amounting to (400) mentors, and after correcting their answers, the grades were arranged from the highest total score to the lowest overall score, then the two extreme groups were determined at (27\%) From the sample members from each group, then the sample members in each group from the upper and lower groups (108) became a guide and a guide, as shown in Table (4). 
Table (4)

The discriminatory power of the paragraphs of the Professional Identity Scale for educational counselors

\begin{tabular}{|c|c|c|c|c|c|c|}
\hline \multirow[t]{2}{*}{$\mathrm{N}$} & \multicolumn{2}{|l|}{ Lower group } & \multicolumn{2}{|l|}{ Top group } & \multirow{2}{*}{$\begin{array}{l}\text { T-test value } \\
\text { Calculated }\end{array}$} & \multirow[t]{2}{*}{ indication } \\
\hline & SMA & $\begin{array}{l}\text { standard } \\
\text { deviation }\end{array}$ & SMA & $\begin{array}{l}\text { standard } \\
\text { deviation }\end{array}$ & & \\
\hline 1 & 3.5 & 0,8 & 4,1 & 0,8 & 5.48 & Function \\
\hline 2 & 3.7 & 0,6 & 4,5 & 0,5 & 10.59 & Function \\
\hline 3 & 4.2 & 0,7 & 5,0 & 0,0 & 11.82 & Function \\
\hline 4 & 3.9 & 0,7 & 4,7 & 0,4 & 10.26 & Function \\
\hline 5 & 3.8 & 0,9 & 4,7 & 0,4 & 4.45 & Function \\
\hline 6 & 3.5 & 0,7 & 4,7 & 0,4 & 15.39 & Function \\
\hline 7 & 3.5 & 0,7 & 4,6 & 0,5 & 13.22 & Function \\
\hline 8 & 3.6 & 0,8 & 4,7 & 0,4 & 12.72 & Function \\
\hline 9 & 3.6 & 0,8 & 4,4 & 0,5 & 8.77 & Function \\
\hline 10 & 3,3 & 0,6 & 4,5 & 0,6 & 14.62 & Function \\
\hline 11 & 3,2 & 0,8 & 4,6 & 0,4 & 16.19 & Function \\
\hline 12 & 3,2 & 1,0 & 4,4 & 0,5 & 11.10 & Function \\
\hline 13 & 3,5 & 0,6 & 4,2 & 0,7 & 7.85 & Function \\
\hline 14 & 3,7 & 0,6 & 4,7 & 0,4 & 14.34 & Function \\
\hline 15 & 3,4 & 0,7 & 4,8 & 0,3 & 19.01 & Function \\
\hline 16 & 3,6 & 1,1 & 4,8 & 0,4 & 10.60 & Function \\
\hline 17 & 4,2 & 0,6 & 4,9 & 0,1 & 11.90 & Function \\
\hline 18 & 3,7 & 0,9 & 4,7 & 0,5 & 10.04 & Function \\
\hline 19 & 3,7 & 0,7 & 5,0 & 0,0 & 19.21 & Function \\
\hline 20 & 3,8 & 0,7 & 4,7 & 0,5 & 10.82 & Function \\
\hline 21 & 3,8 & 0,7 & 4,5 & 0,5 & 8.41 & Function \\
\hline 22 & 3,6 & 0,8 & 4,6 & 0,4 & 11.56 & Function \\
\hline 23 & 4,0 & 0,9 & 4,9 & 0,2 & 10.21 & Function \\
\hline
\end{tabular}




\begin{tabular}{|c|c|c|c|c|c|c|}
\hline 24 & 3,7 & 0,7 & 4,8 & 0,3 & 14.94 & Function \\
\hline 25 & 4,0 & 0,8 & 4,9 & 0,1 & 11.54 & Function \\
\hline 26 & 3,9 & 0,8 & 4,8 & 0,3 & 10.89 & Function \\
\hline 27 & 2,9 & 0,8 & 4,5 & 0,6 & 16.55 & Function \\
\hline 28 & 3,4 & 0,8 & 4,6 & 0,5 & 13.15 & Function \\
\hline 29 & 4,1 & 0,7 & 4,5 & 0,6 & 4.48 & Function \\
\hline 30 & 4,1 & 0,7 & 4,8 & 0,3 & 9.50 & Function \\
\hline 31 & 3,7 & 0,9 & 4,2 & 0,8 & 4.29 & Function \\
\hline 32 & 2,6 & 1,0 & 4,2 & 0,6 & 14.19 & Function \\
\hline 33 & 3,8 & 0,6 & 4,7 & 0,6 & 11.20 & Function \\
\hline 34 & 3,4 & 0,5 & 4,7 & 0,4 & 21.00 & Function \\
\hline 35 & 3,7 & 0,7 & 4,5 & 0,5 & 9.61 & Function \\
\hline 36 & 4,1 & 0,9 & 4,5 & 0,6 & 3.82 & Function \\
\hline 37 & 4,0 & 0,8 & 4,7 & 0,5 & 7.67 & Function \\
\hline 38 & 3,1 & 0,8 & 4,1 & 0,9 & 8.59 & Function \\
\hline 39 & 3,6 & 0,5 & 4,7 & 0,5 & 16.09 & Function \\
\hline 40 & 3,4 & 0,7 & 4,8 & 0,3 & 19.05 & Function \\
\hline 41 & 3,6 & 0,7 & 4,6 & 0,5 & 12.02 & Function \\
\hline 42 & 3,5 & 0,9 & 4,4 & 0,8 & 7.73 & Function \\
\hline 43 & 3,7 & 0,8 & 4,5 & 0,5 & 8.77 & Function \\
\hline 44 & 3,5 & 0,7 & 4,8 & 0,3 & 17.65 & Function \\
\hline 45 & 3,4 & 0,7 & 4,3 & 0,8 & 8.75 & Function \\
\hline 46 & 3,5 & 0,6 & 4,8 & 0,4 & 18.64 & Function \\
\hline 47 & 3,8 & 0,6 & 4,7 & 0,5 & 11.91 & Function \\
\hline 48 & 3,8 & 0,5 & 4,9 & 0,1 & 22.31 & Function \\
\hline 49 & 4,1 & 0,5 & 4,8 & 0,3 & 12.41 & Function \\
\hline
\end{tabular}




\begin{tabular}{|l|r|r|r|r|r|l|}
\hline 50 & 3,6 & 0,7 & 4,9 & 0,1 & 19.01 & Function \\
\hline
\end{tabular}

It is clear from Table (6) that all the values of the paragraphs discrimination coefficients, the professional identity measure, are statistically significant.

\section{Correlation of the paragraph score with the overall score of the scale:}

The correlation of the paragraph score with the overall score of the scale is an indicator of the veracity of the paragraph and an indicator of the homogeneity of the paragraphs in its measurement of the phenomenon (Allen, 1979: 194). To calculate the correlation of the score of each paragraph with the overall score of the scale, the researcher used the Pearson correlation coefficient, where the results were as shown in Table (8)

Table (8)

The values of the coefficients for correlating the paragraph score with the overall score of the professional identity scale

\begin{tabular}{|c|c|c|c|c|c|c|}
\hline $\mathrm{N}$ & $\begin{array}{l}\text { Realistic } \\
\text { level }\end{array}$ & Technical level & $\begin{array}{l}\text { Social } \\
\text { level }\end{array}$ & Traditional level & $\begin{array}{l}\text { Mental } \\
\text { level }\end{array}$ & Adventurous level \\
\hline 1 & 0,22 & 0,46 & 0,41 & 0,62 & 0,58 & 0,67 \\
\hline 2 & 0,51 & 0,54 & 0,43 & 0,58 & 0,44 & 0,47 \\
\hline 3 & 0,56 & 0,64 & 0,66 & 0,30 & 0,32 & 0,68 \\
\hline 4 & 0,46 & 0,61 & 0,49 & 0,48 & 0,47 & 0,57 \\
\hline 5 & 0,53 & 0,36 & 0,44 & 0,31 & 0,42 & 0,62 \\
\hline 6 & 0,62 & 0,59 & 0,47 & 0,59 & 0,61 & 0,55 \\
\hline 7 & 0,62 & 0,60 & 0,56 & 0,44 & 0,65 & 0,59 \\
\hline 8 & 0,54 & 0,53 & 0,63 & & 0,47 & \\
\hline 9 & & & 0,47 & & & \\
\hline 10 & & & 0,54 & & & \\
\hline
\end{tabular}

\section{Factor analysis}

It is a statistical procedure that supports the validity of the test, the method of factor analysis has been employed to a great extent in developing personality tests and measures of intelligence and mental abilities because of the support and evidence provided by this method of the test concept. (Al-Tariari, 1997: 264_265) and Table (6) shows the results of this analysis of the Occupational Identity Scale. 
Table (9)

The value of factor analysis for the professional identity scale

\begin{tabular}{|l|l|l|l|l|l|l|}
\hline $\mathbf{N}$ & $\begin{array}{l}\text { Realistic } \\
\text { level }\end{array}$ & Technical level & $\begin{array}{l}\text { Social } \\
\text { level }\end{array}$ & Traditional level & $\begin{array}{l}\text { Mental } \\
\text { level }\end{array}$ & Adventurous level \\
\hline 1 & & 0,30 & 0,33 & & 0,40 & 0,60 \\
\hline 2 & 0,37 & 0,33 & & & 0,37 & \\
\hline 3 & 0,55 & 0,55 & 0,53 & 0,38 & 0,46 & 0,50 \\
\hline 4 & 0,43 & 0,47 & 0,47 & 0,62 & 0,47 & 0,55 \\
\hline 5 & 0,53 & 0,35 & 0,40 & & & 0,60 \\
\hline 6 & 0,53 & 0,54 & 0,43 & & 0,49 & 0,53 \\
\hline 7 & 0,57 & 0,54 & 0,48 & 0,42 & 0,53 & 0,46 \\
\hline 8 & 0,38 & 0,49 & 0,59 & & 0,33 & \\
\hline 9 & & & 0,38 & & & \\
\hline 10 & & & 0,39 & & 0,36 & \\
\hline Latent root & 9,5 & \multicolumn{7}{|l}{} \\
\hline variance & 19,1 &
\end{tabular}

\section{Indicators of honesty and reliability of the scale First: honesty}

Validity is one of the important characteristics that must be taken care of in building tests, and when the researcher is scientifically sure that the test measures the phenomenon he wants to study or diagnose, then the test is considered valid, so the honest test is that test that is able to measure the characteristic or phenomenon for which it was set. (Al-Zawba'i et al., 1980. Therefore, the researcher verified the validity of the professional identity levels scale through the following indicators:

\section{A- Face Validity:}

It refers to the extent to which the test was measured for the purpose for which it was set outwardly through the agreement of the judgments 'estimates on the degree of the test's measure of the characteristic, and the apparent validity means the general appearance of the test in terms of vocabulary and how it was formulated and the extent of its clarity. (Al-Azzawi, 2007: 94) The researcher verified the apparent validity For the scale when the items of the scale were presented to a group of referees, who numbered (19) arbitrators.

\section{B- Construct Validity:}

The sincerity of the construct means the extent to which the test measures a specific behavioral feature or phenomenon, so the researcher in this type of honesty tries to know the nature of the behavioral phenomenon that the test seeks to measure. (Al-Zobaie and others, 1980: 43) The validity of the construction was verified by relying on several indicators previously presented, namely The correlation of a score with the paragraph with the overall score of the scale, the correlation of the paragraph score with the total score of the field to which it belongs, and the procedures for factor analysis (global validity).

Reliability:

It is defined as measuring the instrument that we want with a high degree of accuracy, that is, we get the same results when re-testing. (Atwan and Mattar, 1971: 112) The stability factor is designed to provide a quantitative estimate of the consistency or accuracy of the measurement. Therefore, the reliability factor is used for one of two purposes. The first is that it expresses the accuracy of the test itself As a second tool, it provides an assessment of the consistency of the subject's performance on the test. The researcher extracted the stability of the scale in two ways:

1- Test-Retest Method:

For the purpose of extracting the stability, the scale was applied to the stability sample of (100) mentors who were tested in a random way and after two weeks of the first application sample, the scale was applied a second time to the same sample and the correlation coefficient between the two applications was calculated, as the stability coefficient was as follows: The first level (0.56), the second level (0.79), the third level (0.92), the fourth level 
(0.80), the fifth level (0.76), the sixth level (0.65) and the overall one (0.94), which is a good stability coefficient.

2- The Alfa Cranach equation (internal consistency): The Alpha Cronbach coefficient of identity levels was as follows: the first level $(0,57)$, the second level $(0,67)$, the third level (0.68), the fourth level (0.46), the fifth level $(0.65)$ and the sixth level $(0,68)$.
Final image of the scale

The scale consists in the final form of (50) items divided into six levels: the realistic environment, the artistic environment, the social environment, the traditional environment, the mental environment, and the adventurous environment.

Table (10)

Statistical indicators of the Occupational Identity Scale

\begin{tabular}{|l|l|l|}
\hline $\mathbf{N}$ & data & Professional identity \\
\hline 1 & Sample volume & \\
\hline 2 & SMA & 200,9 \\
\hline 3 & Mediator & 200,9 \\
\hline 4 & Vein & 202,0 \\
\hline 5 & standard deviation & 15,4 \\
\hline 6 & variance & 238,5 \\
\hline 7 & skewness & 0,2 \\
\hline 8 & Flatulence & 0,1 \\
\hline 9 & Term & 70 \\
\hline 10 & The smallest degree & 246 \\
\hline 11 & Highest score & 23 \\
\hline
\end{tabular}

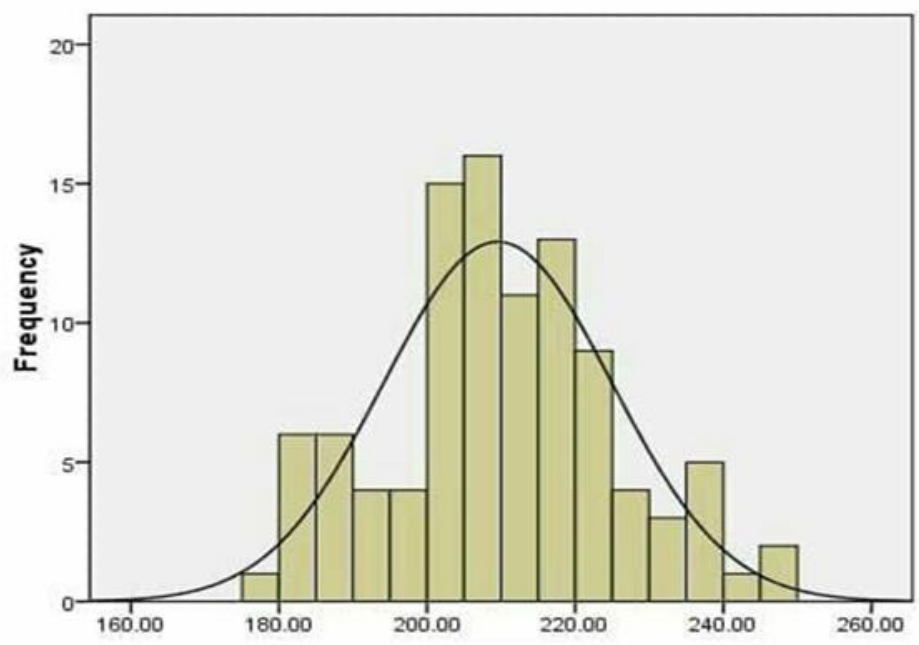

\section{THE FOURTH CHAPTER :}

\section{IDENTIFYING THE LEVELS OF PROFESSIONAL IDENTITY OF EDUCATIONAL COUNSELORS}

Identifying the levels of professional identity of educational counselors

To verify this current goal, the researcher used the t-test for one sample in order to find out the significance of the difference between the mean of the sample scores and the hypothetical average of the scale, where the results were as shown in the table (11) 
Table (11)

Results of the T-test for one sample to find out the significance of the difference between the mean of the sample scores and the assumed average of the levels of the Occupational Identity Scale

\begin{tabular}{|l|r|r|r|r|l|}
\hline Levels & Arithmetic mean & $\begin{array}{l}\text { standard } \\
\text { deviation }\end{array}$ & Hypothesized mean & T-value & $\begin{array}{l}\text { Indication level } \\
0.05\end{array}$ \\
\hline Realistic level & 33,7 & 3,0 & 24 & 32,3 & Function \\
\hline Technical level & 32,5 & 3,6 & 24 & 23,7 & Function \\
\hline Social level & 43,7 & 3,7 & 30 & 36,2 & Function \\
\hline Traditional level & 28,3 & 2,8 & 21 & 25,6 & Function \\
\hline Mental level & 41,2 & 3,9 & 30 & 28,6 & Function \\
\hline Adventurous level & 29,9 & 0,3 & 21 & 29,9 & Function \\
\hline Full identity & 200,9 & 15,4 & 150 & 38,5 & Function \\
\hline
\end{tabular}

The tabular T value at the level of significance (0.05) and at the degree of freedom (399) equals (1.96)

\section{Interpret and discuss results}

It is clear from the goal that educational counselors have a high degree of professional identity at all levels, which indicates that counselors have a clear vision of their professional goals and the professional tasks that must be adhered to and achieved. This is what Holland emphasized that the professional identity expresses "the extent of the clarity of the image that he possesses ,The individual about his current career plans, goals, tendencies, talents, and abilities, or in a simpler way, where the individual falls into the professional awareness "(Abdel Aziz and Ataiwi, 2004: 154_155). This high percentage indicates the extent of the mentors' compatibility with their work, the extent of job satisfaction, and the extent of their possession of professional awareness.

\section{Recommendations:}

1. Providing counseling centers in universities with the scale of professional identity in order to benefit from the concept in enhancing the capabilities of educational counselors.

2. Establishing programs to enhance the concept of professional identity for educational counselors.

3. Intensifying training courses or lessons for educational counselors and coordinating with university teachers in the psychological counseling specialization in order to establish these training courses.

\section{The proposals:}

1- Preparing a training program to develop the professional identity of other mentors

2- Study the research variable, the professional identity and its relationship to some variables such as (professional commitment, social intelligence).

\section{REFERENCES}

- Amina, Carrie Nadia (2012) The Algerian Factor Between Professional Identity and Community Culture, College of Humanities and Sciences

- $\quad$ Abu Attiyah, Siham Darwish (2015) Theories of Guidance and Professional Growth, Dar Al-Fikr Publishers and Distributors, Amman, Jordan

- $\quad$ Ben Qaqqa, Souad, Massoudi, Kulthum (2019) The professional identity of Algerian working women in light of the requirements of human security, Faculty of Human and Social Sciences, Algeria 
- Hussein, Hisham Barakat Bishr (2017) Survey of Professional Identity Levels for Primary Mathematics Teachers, Journal of the College of Basic Education for Educational and Human Sciences, University of Babylon, Issue 32

- Al-Khouli, Hadeel Mostafa (2018) A proposed conception to develop the university's professional identity in light of the conscious partnership with the productive community, Journal of Educational Sciences, Second Issue

- $\quad$ Al-Zobaie, Abdul-Jalil Ibrahim, Bakr, Muhammad Elias, Al-Kinani Ibrahim Abdel-Hassan (1980) Psychological tests and measures, Dar Al-Kutub Directorate for Printing and Publishing, Mosul

- $\quad$ Al-Zubaidi, Abdul-Qawi Salem, Al-Kahali, Salem bin Nasser (2014), the differences between gender, grade, and anxiety in cases of professional identity among ninth and tenth grades students in the Sultanate of Oman, Amarabac Magazine, Volume Five, Number Thirteenth

- Al-Shorfa, Abeer Fathy (2011) the professional self of counselors in educational counseling work in the Gaza Strip, the Islamic University, Gaza

- Abdul Aziz, Saeed, Ataiwi, Jawdat Ezzat (2004) School guidance, House of Culture for Publishing and Distribution, Amman, Jordan

- $\quad$ Abdul Hadi, Jawdat Ezzat, Al-Ezzah, Saeed Hosni (2012) Vocational Guidance and Its Theories, House of Culture for Publishing and Distribution, Amman, Jordan

- $\quad$ Abbas, Muhammad Khalil, Nofal, Muhammad Bakr, Al-Absi, Muhammad Mustafa, Abu Awwad, Faryal Muhammad (2016) Introduction to Research Methods in Education and Psychology, Dar Al-Masirah for Publishing and Distribution, Amman

- $\quad$ Abdul Aziz, Saeed, Ataiwi, Jawdat Ezzat (2004) School guidance, House of Culture for Publishing and Distribution, Amman, Jordan

- $\quad$ Atwan, Asaad Hussein, Matar, Youssef Khalil (1971) Scientific Research Curricula, Dar Al-Kutub Al-Alami, Beirut

- Al-Azzawi, Rahim Yunus Crowe (2007) Al-Manhal in Educational Sciences: Measurement and Evaluation in the Educational Process, Dar Tigris, Amman, Jordan

- $\quad$ Meshri, Soulaf (2018) Teacher's Professional Identity and Its Relation to Commitment to Professional Ethics, AlJamea Journal in Psychological Studies and Educational Sciences, Ninth Issue, Algeria

- $\quad$ Al-Hadi, Jawdat Ezzat Abd, Al-Ezzah, Saeed Hosni (2014) Vocational Guidance and Its Theories, House of Culture for Publishing and Distribution, Amman, Jordan

- $\quad$ Al-Masoud, Hala Farouk, Tannous, Adel George (2015) codifying the list of preferences for John Holland for the Jordanian environment, Educational Sciences, Volume 42, Issue 1

- The Ministry of Education (1988): The General Educational Guide for Evaluation and Examinations, Directorate of Educational Assessment and Guidance.

- Muhammad, Muhammad Hani (2014) Modern organizational behavior, Al-Moataz Publishing and Distribution House, Jordan

- Jungers, M. Christin ,Gregoire , Jocelyn (2013) Counseling ethics : philosophical and professional foundations , Springer pubishing company, LIC

- J Schwartz, Seth (2001) The evolution of eriksonian and neo_friksonian theory and research : A Review and Integration 
- $\quad$ Webb, A. Stephen (2017) Professional identity and social work ,New York ,States of America.

- $\quad$ Brown ,D. Steven, Lent, W. Robert (2005) Career development and counseling :putting theory and research to work, WILEY 